\title{
THE BURIAL OF THE LATE BRONZE AGE FROM MOUND 9 IN THE PASTURE BY THE TOWN OF POKROVSK: EXCAVATIONS BY P.N. SHISHKIN
}

\author{
Nikolay M. Malov \\ Saratov State University, Saratov, Russian Federation
}

\begin{abstract}
V. P. Shilov had made fundamental contribution to archaeology of Southeastern Russia and the Lower Volga region. His academic heritage is represented by numerous artefacts and materials from archaeological investigations. Among the wide range of scientific subjects, the archaeologist kept giving attention to studying the Bronze Age monuments. Much importance is attached to his research in the development of early nomadic cattle breeding and private ownership of cattle during the epoch of paleometals, on the problems of metallurgy and specifying the Bronze Age burials of foundrymen. He was interested in the issues of comprehending the cultural assignment of the Pokrovsktype monuments. Knives make the most common category among the metal items of that epoch in the Lower Volga region. Over 100 knives come from the Pokrovsk and the timber-grave culture monuments in the Lower Volga region. Their functional purposes were dissimilar. There are sparse burial complexes comprising two knives of different types. Those differ in shapes and parameters. Generally, one knife is larger and longer, while the other one is small and short. The Late Bronze Age grave complexes with two and more knives in Northern Eurasia deserve special analysis. P.N. Shishkin has examined one of those in a mound within the southwestern group near the town of Pokrovsk. The grave goods are represented by a pair of copper knives and hand-molded vessels. In terms of the rite and goods characteristics, this corresponds to the similar complexes of the Pokrovsk-timber-grave stage of the Late Bronze Age.

Key words: burial mound, grave goods, the Late Bronze Age, Pokrovsk culture, timber-grave culture, Lower Volga region, V.P. Shilov.

Citation. Malov N.M. The Burial of the Late Bronze Age from Mound 9 in the Pasture by the Town of Pokrovsk: Excavations by P.N. Shishkin. Vestnik Volgogradskogo gosudarstvennogo universiteta. Seriya 4, Istoriya. Regionovedenie. Mezhdunarodnye otnosheniya [Science Journal of Volgograd State University. History. Area Studies. International Relations], 2018, vol. 23, no. 3, pp. 29-36. (in Russian). DOI: https://doi.org/10.15688/ jvolsu4.2018.3.3
\end{abstract}

УДК 920(470.44/.47) |637.7|+929 Шилов

ББК 63.4(235.54)
Дата поступления статьи: 05.02.2018

Дата принятия статьи: 10.04.2018

\section{ПОГРЕБЕНИЕ ЭПОХИ ПОЗДНЕЙ БРОНЗЫ ИЗ КУРГАНА 9 НА ВЫГОНЕ ГОРОДА ПОКРОВСКА: РАСКОПКИ П.Н. ШИШКИНА}

\author{
Николай Михайлович Малов \\ Саратовский национальный исследовательский государственный университет им. Н.Г. Чернышевского, \\ г. Саратов, Российская Федерация
}

Аннотация. В.П. Шилов внес фундаментальный вклад в археологию юго-востока России и Нижнего Поволжья. Среди широкого диапазона научных тем археолог постоянно уделял существенное внимание изучению памятников бронзового века. Важную роль сыграли его работы, посвященные исследованию проблем становления раннего кочевого скотоводства и частной собственности на скот в эпоху палеометаллов, металлургии и выделения погребений мастеров-литейщиков бронзового века. Его интересовали вопросы, связанные с осмыслением культурной принадлежности памятников покровского типа. В военные годы он кратковременно бывал и проживал в городах Энгельс (бывший Покровск) и Саратов. В 1920 г. П.Н. Шиш- 
кин исследовал могилу в одной из насыпей юго-западной группы около г. Покровска. Погребальный инвентарь представлен парой медных ножей и лепных сосудов эпохи поздней бронзы. Среди металлических вещей данной эпохи в Нижнем Поволжье самой распространенной категорией являются ножи. С памятников покровской и срубной культур северной территории Нижнего Поволжья происходит более 100 ножей. Есть немногочисленные погребальные комплексы с двумя ножами различного типа. Они отличаются друг от друга по форме и параметрам. Один нож более крупный и длинный, а другой - небольшой и короткий. Функциональное предназначение ножей было не однотипным. По обрядовым показателям и инвентарю погребение соответствует аналогичным комплексам покровско-срубной стадии позднего бронзового века.

Ключевые слова: курган, погребальный инвентарь, поздний бронзовый век, покровская культура, срубная культура, Нижнее Поволжье, В.П. Шилов.

Цитирование. Малов Н. М. Погребение эпохи поздней бронзы из кургана 9 на выгоне города Покровска: раскопки П.Н. Шишкина // Вестник Волгоградского государственного университета. Серия 4, История. Регионоведение. Международные отношения. - 2018. - Т. 23, № 3. - С. 29-36. - DOI: https://doi.org/10.15688/jvolsu4.2018.3.3

\section{Введение}

Валентин Павлович Шилов внес фундаментальный вклад в археологию юго-востока России и Нижнего Поволжья второй половины $\mathrm{XX}$ века. Его научное наследие представлено опубликованными трудами и артефактами, полученными в результате многолетних академических полевых исследований. Важную роль сыграли работы археолога, посвященные формированию частной собственности на скот и становлению кочевого скотоводства, изучению металлургии бронзового века. Его интересовали вопросы, связанные с осмыслением культурной принадлежности памятников покровского типа. Например, исследователь возражал против попытки П.Д. Либерова считать нижневолжские сосуды с примесью толченой ракушки - абашевскими [14, с. 109]. Он постоянно уделял существенное внимание изучению памятников бронзового века.

Валентин Павлович - участник Великой Отечественной войны [7, с. 251]. В эти годы он кратковременно проживал в городах Энгельс (бывший Покровск) и Саратов. В декабре 1941 г. В.П. Шилов окончил Ленинградское Краснознаменное артиллерийское училище, эвакуированное тогда в г. Энгельс [1, с. 43]. После тяжелого ранения молодой археолог стал инвалидом и лечился в Саратовском госпитале. Здесь он готовился к поступлению в аспирантуру, используя литературу научной библиотеки Саратовского государственного университета [11, с. 4-5]. Валентин Павлович с искренней благодарностью вспоминал, как ему приносили раритетные издания из отдела редких книг университетской библиотеки.
В 1980-е гг. он неоднократно посещал г. Саратов, где однажды выступил перед студентами-археологами истфака СГУ с докладом о повозках эпохи ранней-средней бронзы. Валентин Павлович был научным руководителем диссертационных исследований по проблемам неолита - энеолита - бронзового века Нижнего Поволжья у нескольких археологов - выпускников СГУ (В.И. Мельник, В.А. Лопатин, А.И. Юдин). Исследователь один из авторов САИ по срубной культуре Волго-Уральского междуречья, опубликовал статьи в сборнике «Археология ВосточноЕвропейской степи», изданном СГУ.

В эпоху поздней бронзы в Нижнем Поволжье самой распространенной категорией металлоемких вещей являются ножи. К середине XX в. наибольшее количество ножей срубного типа было найдено в Поволжье [2, с. 54]. К началу 1990-х гг. в памятниках покровского культурного типа Нижнего Поволжья было учтено 45 ножей, происходящих из $32(24,5 \%)$ могил и 4 поселений [3, с. 12]. Обычно они входят в состав погребального инвентаря, но встречаются и на бытовых памятниках (Нижняя Красавка, Медведицкое, Ружьевка, Хмельное и др.). По неполным данным сейчас только в северных районах Нижнего Поволжья известно более 100 ножей эпохи поздней бронзы. Наибольшее их число происходит из Покровской (юго-восточная группа), Натальинской, Осиновской и Бережновских групп. Широкое распространение ножей объясняется тем, что они являлись повседневным оружием пастухов-скотоводов [2, c. 89]. Находки ножей преимущественно связаны со взрослыми мужскими захоронениями, 
но изредка встречены в женских и подростковых могилах.

Особого внимания заслуживают немногочисленные погребальные комплексы с двумя ножами. Один из них П.Н. Шишкин исследовал весной 1920 г. около Покровска в кургане 9. Однако погребение до сих пор не введено полностью в научный оборот и не анализировалось, что и является целью данной публикации.

\section{Курган 9 на общественном выгоне г. Покровска}

Результаты исследования кургана воспроизводятся по тексту статьи Петра Николаевича с сохранением авторской орфографии и пунктуации [15, с. 25-26]:

«Выемкой глины срезана часть его западной полы, но, по оставшейся части, возможно судить о его прежних размерах и форме. С округлой формы основанием высшей точкой над северной полой курган имеет размеры, числя их от высшей точки к югу 21 метр, к северу - 15 мет. к западу 3,5 мет и на восток 25,5 мет. Вскрытие было начато колодцем протяженностью с С. на Ю. $-8,5$ мет. и с В. на 3 - 6,5 метр. При сьемке первого стыка в Ю.-В. углу колодца обнаружено погребение без каких либо следов гроба, на левом боку лицом к востоку, на левой щеке с головой, ориентированной на С.-В. и согнутыми конечностями. Скелет человека был замечен не тотчас же, благодаря чему оказались срезанными фаланги пальцев правой ноги и коленная кость той же ноги сдвинута с места, а также не обнаружены благодаря тому же, повидимому, кисти рук и срезан конец бронзового ножа. Грудные, поясничные позвонки представляют прямую линию, шейные позвонки и череп несколько отклонены к востоку. Руки согнуты таким образом, что кисти должны были сходиться у подбородка. Бедреные кости и позвоночный столб образуют угол в 90; бедреные и голенные кости образуют угол около $30^{\circ}$. Пяточные кости находились на прямой, проведенной через позвоночник. Возле черепа находился бронзовый нож, длинная ось которого направлена была с 3. на В. На месте сочленения запястья и локтевой кости правой руки, поверх последних, лежал другой бронзовый нож, длинная ось которого имела теже направления, с той лишь разницей, что первый был обращен острием к 3., а ручкой к $\mathrm{B}$, а второй обратно, острием к В. и ручкой к 3.-В 44 сант. К Ю.-В. от колен костяка небольшой глиняный горшочек с рисунком по верхнему краю в виде 2-х ромбов и 2-х параллельных штрихов возле наружного края левого ромба. Сосуд имеет 2 сквозных небольших отверстия на верхней своей части, повидимому, предназначенных для продевания веревочек при подвешивании сосуда над огнем. В 44 сант. к Ю-3. от пяточной кости находился другой сосуд, распавшийся на части под давлением земли и, по склеивании его, имеющий баночную форму без следов орнамента; длина скелета: от темени до вертлуга бедренных костей 49 сант., бедренная кость 45 сан. и голенная с пяточной 34 сант. После снятия еще 2-х стыков работа была прекращена».

\section{Музейная коллекция, интерпретация и выводы}

Инвентарь представлен двумя лепными плоскодонными сосудами и парой бронзовых ножей.

Керамические сосуды. Округлобокий сосуд баночной формы с орнаментом стоял около колен (рис. 1, 1). Емкость банки 0,4 литра. Цвет заглаженной поверхности светло-коричневый, глина в изломе черная с примесью шамота и небольшого количества дробленой раковины. Ниже венчика в сырой глине проделаны два сквозных отверстия диаметром 0,5 см, расположенные друг против друга. Около одного из них резной (или выполнен углом гладкого штампа) горизонтальный орнамент из 2 ромбов и 2 коротких параллельных линий. Диаметр по венчику - 10 см, по дну - 8,5 см. Высота банки 8,5 см. Днище с закраиной, низким и широким «псевдо-поддоном», что указывает на особенности конструирования формы сосуда. Банка грубой выделки относится к типу с закрытым устьем, поскольку венчик загнут внутрь. Наибольший диаметр 11 см - приходится на середину тулова. Банки такой формы и орнаментальный сюжет из ромбов широко представлены в срубной культуре региона. 


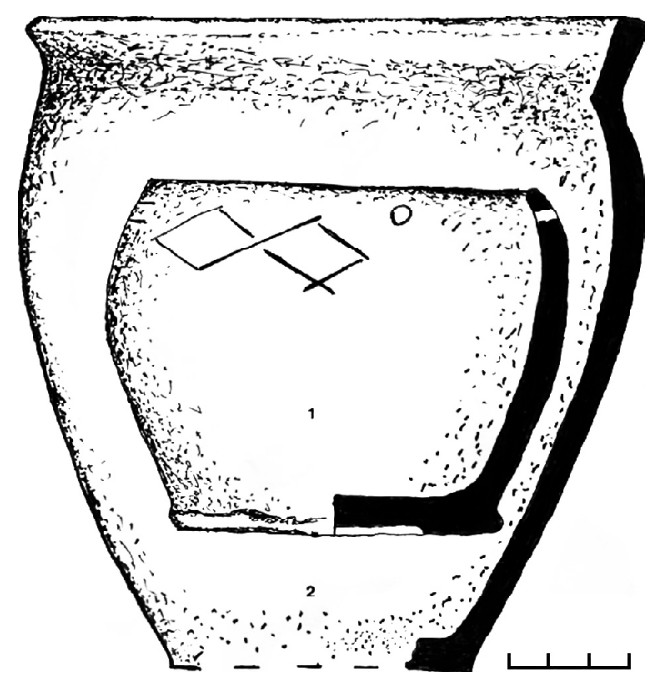

Рис. 1. Покровский курган 9. Раскопки П.Н. Шишкина. Керамические сосуды

Fig. 1. Pokrovsk mound 9. Excavations by P.N. Shishkin. Ceramic vessels

По мнению П.Н. Шишкина, через отверстия в верхней части продевались веревочки для подвешивания сосуда над огнем. Скорее всего, через эти отверстия действительно проходила «веревочка» для крепления деревянной крышки или подвешивания маленького сосуда, но не над огнем, где она бы сгорела. В погребениях покровской и срубной культур Нижнего Поволжья встречено более 30 небольших острореберных, округлобоких и биконических сосудиков с двумя отверстиями под веничком, а иногда 2 керамические крышки с отверстиями [3, с. 9-10]. Исследователи чаще всего интерпретируют их как сосуды ритуального характера, с отверстиями для подвешивания или типа курильниц с крышками. Для этой и другой посуды использовались не только глиняные, но и не сохранившиеся деревянные крышки. Вероятнее всего, отверстия связаны с сосудами, у которых были крышки. Через них к устью сосуда плотно привязывалась крышка. Это не только позволяло сохранять тепло, но и препятствовало испарению их жидкого содержимого, а также предохраняло от доступа насекомых и грызунов к находящемуся там продукту.

Распавшийся на фрагменты, округлобокий сероглиняный сосуд колоколовидной формы, без орнамента, стоял около пяточной кости (рис. 1, 2). Его емкость - 1,5 литра. Поверхность светло-коричневая с темными пятнами и едва заметными полосками от заглаживания. Излом черный, в тесте примесь дробленой раковины. Венчик - с внутренним уступом, отогнут наружу, его срез прямой. Высота сосуда - 16,5-17 см, диаметр по дну 7-8 см, по венчику, предположительно, не менее 15,5-16 см. Наибольший диаметр приходится на верхнюю треть тулова. Колоколовидные горшки с внутренним уступом под венчиком составляют в покровской культуре Нижнего Поволжья более одной трети керамики [2, c. 10-11].

Бронзовые ножи. Короткий нож с ребром жесткости и со «срезанным концом» пера (рис. 2,2 ) сохранился в длину на 7,5-7,6 см. Длина рукояти от острого конца черешка до середины перекрестия - 2,7-2,8 см. Ширина перекрестия - 2 см, перехвата - 1,8 cм. Максимальная ширина пера $-2,5$ см.

Второй - более длинный нож с сохранившимся концом пера (рис. 2, 1). Общая длина $-15,5$ см, длина рукояти от прямого конца черешка до середины перекрестия - 4,5 см. Ширина перекрестия - 3 см, перехвата 2,2 см. Максимальная ширина пера $-3,4$ см.

Оба ножа традиционно считают срубными. На эту пару предметов первым обратил внимание Б.Г. Тихонов, справедливо включивший их в две разные группы. При этом исследователь опубликовал рисунок только одного - более длинного ножа с ребром жесткости. Это изделие он отнес ко второй группе [12, c. $74-75$, с. 110 , табл. VIII, 27 ; с. 113 , табл. XVI, 3]. В последующем Е.Н. Черных опубликовал оба ножа и определил, что они изготовле- 


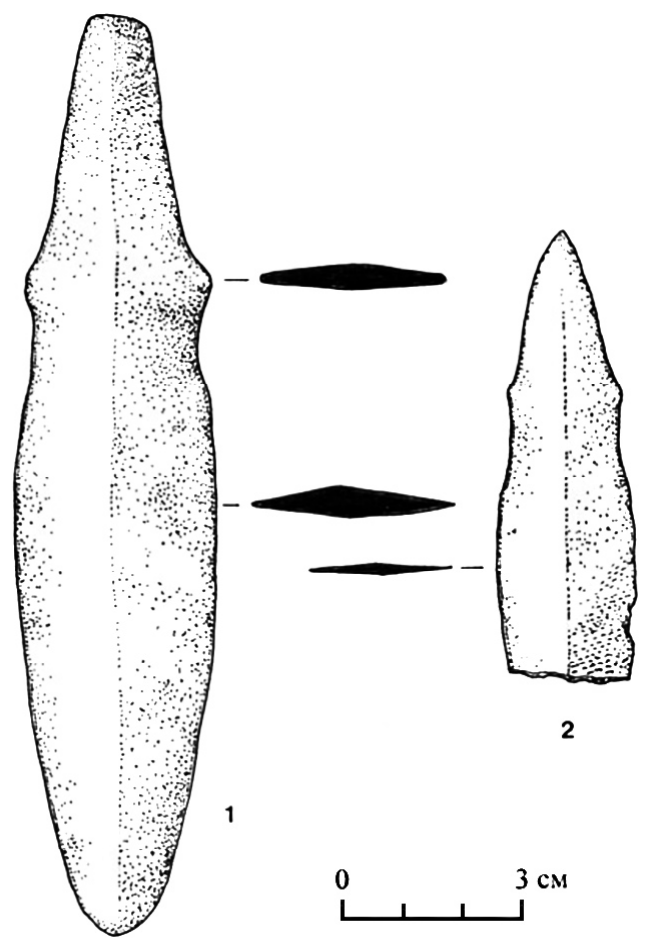

Рис. 2. Покровский курган 9. Раскопки П.Н. Шишкина. Бронзовые ножи

Fig. 2. Pokrovsk mound 9. Excavations by P.N. Shishkin. Bronze knives

ны из меди мышьяковой или сурьмяно-мышьяковой волго-камской химико-металлургической группы ВК $[13$, с. 67 , рис. 58,12 ; с. 129 , табл. I, № 1661]. Отметим, что эта химикометаллургическая группа преобладает среди цветного металла покровской культуры лесостепного и степного Поволжья [6, с. 86].

Немногочисленные погребальные комплексы с двумя ножами разного типа есть в Покровских, Усатовских, Натальинских и других курганах. При этом один нож более крупный, а другой меньшего размера. Короткие ножи интерпретируют противоречиво - от наконечников стрел до бритв. Высказывалось мнение, что небольшой «ножичек» из рассматриваемого покровского погребения мог быть дротиком [9, с. 7]. Присутствие двух ножей разного типа в одном погребении указывает на то, что их функциональное предназначение было неоднородным. Это подтверждает предположение, ранее высказанное О.А. Кривцовой-Граковой [2, с. 54].

Место расположения кургана. П.Н. Шишкин раскапывал курган, находившийся на краю карьера кирпичного завода, расположенного по соседству с заводом Куценко [15, с. 25]. П.С. Рыков уточнил, что П.Н. Шишкин от- крыл погребение в третьей курганной группе за железнодорожным полотном [9, с. 7]. Судя по плану древних памятников, опубликованному И.В. Синицыным, П.Н. Шишкин исследовал погребение в одной из насыпей югозападной курганной группы. В начале XX в. она находилась за полотном железной дроги, на юго-западной окраине современного г. Энгельса, за крупным «Вихляным оврагом» около дороги в с. Квасниковку [10, с. 280 , рис. 1]. В данной группе курганы раскапывались П.С. Рыковым, П.Д. Рау и И.В. Синицыным. Сейчас насыпь практически разрушена карьером и шоссе, но ее остатки можно выявить среди частных домов и приусадебных участков.

Определенный интерес представляет вопрос о том, какой из бытовых памятников можно соотнести с погребением, исследованным П.Н. Шишкиным. Сопоставлению находок одного из селищ с курганными материалами покровских групп уделила внимание Т.М. Минаева. Однако в данном поселении керамика покровской культуры отсутствует, поэтому нет оснований объединять керамику «Покровского селища» с сосудами, найденными П.Н. Шишкиным. Она более связана с северо-западной 
курганной группой [9, с. 7-8]. Сейчас в окрестностях г. Энгельса выявлена серия поселений эпохи поздней бронзы. Ближе всех по расстоянию и фрагментам керамики с данным погребением юго-западной группы можно соотнести два других селища. Именно они расположены около этой группы - на склоне оврага «Вихляного», а также содержат посуду покровской и срубной культур [4, с. 62, № 29-30].

Культурная принадлежность погребения. В кургане фрагментарно исследовалась только часть насыпи, далее раскопки не осуществлялись. Курган раскопан не полностью и не до материка. Захоронение обнаружено после снятия первого штыка, то есть оно было впущено в уже существовавшую насыпь. В публикации П.Н. Шишкин констатировал: «Погребение кургана № 9 относится к поре бронзовых орудий (культура погребений в насыпи), что видно из характерных типов глиняных горшечков и бронзовых ножей, обнаруженных в могиле» [15, с. 26]. П.С. Рыков также рассматривал комплекс как погребение в насыпи и на горизонте бронзовой эпохи $[9$, с. 7$]$.

Сейчас данное захоронение относят к числу памятников срубной эпохи ВолгоУральского междуречья [8, с. 32-33, табл. 1, 20 (22); с. 146, табл. 16, 25-27]. По обрядовым показателям и инвентарю погребение из кургана № 9 соответствует аналогичным комплексам покровско-срубной стадии 2.1 позднего бронзового века [5, с. 96-97]. Сюда включаются сосуществующие комплексы поздней покровской и ранней срубной культур, которые иногда содержат в одной могиле покровскую, покровско-абашевскую и срубную глиняную посуду.

\section{СПИСОК ЛИТЕРАТУРЫ}

1. Алекшин, В. А. Валентин Павлович Шилов - заведующий ЛОИА АН СССР с 14 декабря 1971 г. по январь 1976 г. / В. А. Алешкин // Академическая археология на берегах Невы (от РАИМК до ИИМК РАН, 1919-2014 гг.). - СПб. : Дмитрий Буланин, 2013. - С. 43.

2. Кривцова-Гракова, О. А. Степное Поволжье и Причерноморье в эпоху поздней бронзы / О. А. Кривцова-Гракова. - М. : Изд-во АН СССР, 1955. - 162 c. - (Материалы и исследования по археологии СССР ; № 46).
3. Малов, Н. М. «Абашевские племена» Нижнего Поволжья (Памятники покровского типа) : автореф. дис ... канд. ист. наук / Малов Николай Михайлович. - СПб., 1992.- 16 с.

4. Малов, Н. М. Покровская культура начала эпохи поздней бронзы в северных районах Нижнего Поволжья: по материалам поселений срубной культурно-исторической области / Н. М. Малов // Археология Восточно-Европейской степи. Вып. 5. - Саратов : Научная книга, 2007. - С. 34-92.

5. Малов, Н. М. Культурогенез в эпоху поздней бронзы Нижнего Поволжья // Известия СГУ. Новая серия. Серия «История. Международные отношения». - 2012. - Т. 12, вып. 1. C. $95-100$.

6. Малов, Н. М. Памятники срубной культурно-исторической области в Нижнем Поволжье: концептуальные основы культурогенеза / Н. М. Малов // Древние культуры Юго-Восточной Европы и Западной Азии. - М. : Институт археологии РАН, 2014. - C. 84-92.

7. Памяти Валентина Павловича Шилова // Российская археология. - 1996. - № 3. - С. 251.

8. Памятники срубной культуры. ВолгоУральское междуречье // Археология России. Т. I/ под ред. Н. М. Малова. - Саратов : Изд-во Сарат. гос. ун-та, 1993. - 204 с. - (Свод археологических источников ; В 1-10).

9. Рыков, П. С. Результаты археологических исследований в Покровском и Хвалынском уездах Саратовской губ., 1922 г. / П. С. Рыков // Труды общества истории, археологии и этнографии при Сарат. гос. ун-те. - Вып. 34, ч. 1. - Саратов : Сарполиграфпром, 1923. - С. 3-19.

10. Синицын, И. В. Памятники родового общества степей Заволжья / И. В. Синицын // Ученые записки СГУ. Выпуск исторический. T. LXVI. - Caратов : Коммунист, 1956. - С. 278-309.

11. Скрипкин, А. С. В.П. Шилов - исследователь древней истории Нижнего Поволжья / А. С. Скрипкин // Нижневолжский археологический вестник. 1998. - Вып. 1.- С. 4-8.

12. Тихонов, Б. Г. Металлические изделия эпохи бронзы на Среднем Урале и в Приуралье / Б. Г. Тихонов // Тихонов Б. Г., Гришин Ю. С. Очерки по истории производства в Приуралье и южной Сибири в эпоху бронзы и раннего железа. - М. : Изд-во Академии наук СССР, 1960. - С. 5-115. - (Материалы и исследования по археологии СССР ; № 90).

13. Черных, Е. Н. Древнейшая металлургия Урала и Поволжья / Е. Н. Черных . - М. : Наука, 1970. 180 с. - (Материалы и исследования по археологии СCCP; № 172).

14. Шилов, В. П. Очерки по истории древних племен Нижнего Поволжья / В. П. Шилов. - Л. : Наука, 1975. - 208 c. 
15. Шишкин, П. Н. Курганы на общественном выгоне г. Покровска / П. Н. Шишкин // Труды общества истории, археологии и этнографии при Сарат. гос. ун-те. - Вып. 34, ч. 1. - Саратов : Сарполиграфпром, 1923. - С. 22-26.

\section{REFERENCES}

1. Alekshin V.A. Valentin Pavlovich Shilov zaveduyushchiy LOIAAN SSSR s 14 dekabrya $1971 \mathrm{~g}$. po yanvar 1976 g. [Valentin Pavlovich Shilov, Head of the Leningrad Branch of the Institute for Archaeology at the USSR Academy of Sciences]. Akademicheskaya arkheologiya na beregakh Nevy (ot RAIMK do IIMK $R A N, 1919-2014$ gg.) [Academic Archaeology on the Banks of the Neva River (from RAHMC to IHMC RAS, 1919-2014)]. Saint Petersburg, DMITRY BULANIN Publ., 2013, p. 43.

2. Krivtsova-Grakova O.A. Stepnoe Povolzhye i Prichernomorye $\mathrm{v}$ epokhu pozdney bronzy [The Steppe Volga Regions and the Black Sea Region in the Late Bronze Age]. Materialy $i$ issledovaniya po arkheologii SSSR. № 46 [Materials and Research on Archaeology of the USSR, Iss. 46]. Moscow, Izd-vo AN SSSR, 1955. 162 p.

3. Malov N.M. "Abashevskie plemena» Nizhnego Povolzhya (Pamyatniki pokrovskogo tipa): avtoref. dis ... kand. ist. nauk ["The Abashevo Tribes" from the Lower Volga Region (The Pokrovsk-Type Monuments). Cand. hist. sci. abs. diss.]. Saint Petersburg, 1992. $16 \mathrm{p}$.

4. Malov N.M. Pokrovskaya kultura nachala epokhi pozdney bronzy $\mathrm{v}$ severnykh rayonakh Nizhnego Povolzhya: po materialam poseleniy srubnoy kulturno-istoricheskoy oblasti [The Pokrovsk Culture of the Early Period of the Late Bronze Age in the Northern Areas of the Lower Volga Region: Based on the Materials from the Settlements of the Timber-Grave Cultural-Historical Area]. Arkheologiya VostochnoEvropeyskoy stepi. Vyp. 5 [Archaeology of the EastEuropean Steppe. Iss. 5]. Saratov, Nauchnaya kniga Publ., 2007, pp. 34-92.

5. Malov N.M. Kulturogenez v epokhu pozdney bronzy Nizhnego Povolzhya [Culture Genesis in the Lower Volga Region during the Bronze Age]. Izv. SGU. Novaya seriya. Seriya Istoriya. Mezhdunarodnye otnosheniya [Izvestiya of Saratov University. New Series. Series: History. International Relations], 2012, vol. 12 , iss. 1, pp. 95-100.

6. Malov N.M. Pamyatniki srubnoy kulturnoistoricheskoy oblasti v Nizhnem Povolzhye: kontseptualnye osnovy kulturogeneza [The Monuments of the Timber-Grave Cultural-Historical Area in the Lower Volga Region: Conceptual Framework of Culture Genesis]. Drevnie kultury Yugo-Vostochnoy
Evropy i Zapadnoy Azii [Ancient Cultures in Southeastern Europe and Western Asia]. Moscow, IA RAN Publ., 2014, pp. 84-92.

7. Pamyati Valentina Pavlovicha Shilova [In Memory of Valentin Pavlovich Shilov]. Rossiyskaya arkheologiya [Russian Archaeology], 1996, no. 3. p. 251.

8. Pamyatniki srubnoy kultury. Volgo-Uralskoe mezhdurechye [Monuments of the TimberGrave Culture. The Volga-Ural Interfluve]. Malov N.M., ed. Arkheologiya Rossii. T. I Svod arkheologicheskikh istochnikov. V 1-10 [Archaeology of Russia. Vol. 1. Corpus of Archaeological Sources. V 1-10]. Saratov, Izd-vo SGU, 1993.204 p.

9. Rykov P.S. Rezultaty arkheologicheskikh issledovaniy v Pokrovskom i Khvalynskom uezdakh Saratovskoy gub. 1922 g. [The Results of Archaeological Investigation in the Pokrovsk and Khvalynsk Districts of the Saratov Province in 1922]. Trudy obshchestva istorii, arkheologii i etnografii pri Sarat. gos. un-te. Vyp. 34, ch. 1. [Works of the Society for History, Archaeology and Ethnography at the Saratov State University. Iss. 34. Part 1]. Saratov, Sarpoligrafprom Publ., 1923, pp. 3-19.

10. Sinitsyn I.V. Pamyatniki rodovogo obshchestva stepey Zavolzhya [Monuments of the Tribal Society in the Trans-Volga Steppes]. Uch. zapiski SGU. Vypusk istoricheskiy. T. LXVI [Proceedings of the Saratov State University. Historical Publications. Vol. LXVI]. Saratov, Kommunist Publ., 1956, pp. 278-309.

11. Skripkin A.C. V.P. Shilov - issledovatel drevney istorii Nizhnego Povolzhya [V. P. Shilov, Researcher of the Ancient History of the Lower Volga Region]. The Lower Volga Archaeological Bulletin, 1998, vol. 1, pp. 4-8.

12. Tikhonov B.G. Metallicheskie izdeliya epokhi bronzy na Srednem Urale i v Priuralye [Metal Products of the Bronze Age from the Middle Urals and the CisUrals]. Tihonov B.G., Grishin Yu.S. Ocherki po istorii proizvodstva $v$ Priuralye i yuzhnoy Sibiri v epokhu bronzy i rannego zheleza / Materialy i issledovaniya po arkheologii SSSR. № 90 [Essays on the History of Production in the Cis-Urals and South Siberia in the Bronze and Early Iron Ages. Materials and Research on the USSR Archaeology. Iss. 90]. Moscow, AN SSSR Publ., 1960, pp. 5-115.

13. Chernykh E.N. Drevneyshaya metallurgiya Urala i Povolzhya [Ancient Metallurgy in the Urals and in the Volga Region]. Materialy $i$ issledovaniya po arkheologii SSSR. № 172 [Materials and Research on the USSR Archaeology. Iss. 172]. Moscow, Nauka Publ., 1970. 180 p.

14. Shilov V.P. Ocherki po istorii drevnikh plemen Nizhnego Povolzhya [Essays on the History of Ancient Tribes of the Lower Volga Region]. Leningrad, Nauka Publ., 1975. 208 p. 
15. Shishkin P.N. Kurgany na obshchestvennom vygone g. Pokrovska [Mounds in the Common Pastures of the Town of Pokrovsk]. Trudy obshchestva istorii, arkheologii i etnografii pri Sarat. gos. un-te.
Vyp. 34, ch. 1 [Works of the Society for History, Archaeology and Ethnography at the Saratov State University. Iss. 34. Part 1]. Saratov, Sarpoligrafprom Publ., 1923, iss. 34, part 1, pp. 22-26.

\section{Information about the Author}

Nikolay M. Malov, Candidate of Sciences (History), Associate Professor, Department of History of Russia and Archaeology, Saratov State University, Astrakhanskaya St., 83, 410012 Saratov, Russian Federation, malovnm@mail.ru, https://orcid.org/0000-0002-0397-923X

\section{Информация об авторе}

Николай Михайлович Малов, кандидат исторических наук, доцент кафедры истории России и археологии, Саратовский национальный исследовательский государственный университет им. Н.Г. Чернышевского, ул. Астраханская, 83, 410012 г. Саратов, Российская Федерация, malovnm@mail.ru, https://orcid.org/0000-0002-0397-923X 